\title{
High levels of vitamin D associated with less ischemic heart disease - a nested case-control study among rural men in Sweden
}

\author{
Sara Holmberg ${ }^{1,2}$, Anna Rignell-Hydbom², Christian H Lindh², Bo AG Jönsson², Anders Thelin ${ }^{3}$, \\ Lars Rylander ${ }^{2}$ \\ ${ }^{1}$ Department of Research and Development, Region Kronoberg, Växjö, Sweden \\ ${ }^{2}$ Division of Occupational and Environmental Medicine, Institute of Laboratory Medicine, Lund University, Lund, Sweden \\ ${ }^{3}$ Department of Public Health and Caring Sciences, Family Medicine and Clinical epidemiological Sections, Uppsala \\ University, Sweden
}

Holmberg S, Rignell-Hydbom A, Lindh Ch. H, Jönsson B, Thelin A, Rylander L. High levels of vitamin D associated with less ischemic heart disease - a nested case-control study among rural men in Sweden. Ann Agric Environ Med. 2017; 24(2): 288-293.

\begin{abstract}
Introduction and objective. Low levels of serum vitamin D have been associated with increased occurrence of ischemic heart disease (IHD), but findings are inconsistent, e.g. seasonal variation is not always considered in the analyses. The aim of this study was to investigate whether vitamin D is associated with IHD among rural middle-aged men in Sweden when seasonal variation is taken into account.

Materials and method. A nested case-control study was performed within a population-based cohort of Swedish farmers and rural residents followed for 20 years. Outcomes were from national health registers. For 276 cases (IHD at any time during follow-up), and for 276 aged-matched controls free of cardiovascular diseases or diabetes, serum levels of vitamin $\mathrm{D}\left(25\right.$-hydroxyvitamin $\mathrm{D}_{3}$ ) were analyzed with liquid chromatography/tandem mass spectrometry (LC/MS/MS), in stored blood samples drawn at the baseline survey in 1990-91. The odds ratio (OR) with 95\% confidence intervals (CI) of IHD for vitamin D-quartiles (based on measured as well as adjusted for month of sampling) was evaluated in logistic regression models; potential confounders were taken into account.

Results. The measured mean vitamin D levels were $27.6 \mathrm{ng} / \mathrm{ml}$ (standard deviation (sd) $8.2 \mathrm{ng} / \mathrm{ml}$ ) and $28.8 \mathrm{ng} / \mathrm{ml}$ (sd 9.0) among cases and controls, respectively. Compared to the quartile with the lowest month-adjusted vitamin D levels, the risk of IHD was significantly lower in the highest quartile $(\mathrm{OR}=0.46,95 \% \mathrm{Cl} 0.25-0.84, \mathrm{p}=0.012)$ in the fully-adjusted model. Conclusion. Rural Swedish men in the highest quartile of serum vitamin D had halved relative risk of IHD, compared to those in the lowest quartile.
\end{abstract}

Key words

coronary heart disease, 25 -hydroxyvitamin $\mathrm{D}_{3^{\prime}}$ prospective study, seasonal variation, agriculture

\section{INTRODUCTION AND OBJECTIVES}

The role of vitamin Dfor calcium homeostasis and bone health is well known. In recent years, an increasing number of studies have reported associations between vitamin $\mathrm{D}$ and many diseases [1-3] and mortality[4, 5]. Low levels of vitamin $\mathrm{D}$ have also been associated with ischemic heart disease (IHD) [6, 7], but findings are inconsistent [8]. Stronger associations have been found for fatal cardiovascular events [9], although to-date supplementation trials have not found conclusive evidence that they have any effect regarding cardiovascular prevention $[8,10]$, or for mortality among the elderly[11].

Research into the mechanisms and causal links between vitamin $\mathrm{D}$ and cardiovascular disease are inconclusive. Whether vitamin $\mathrm{D}$ deficiency/insufficiency is a general risk factor, or if a sufficient level is a general health indicator is not clear.There are several possible mechanisms that could link vitamin D deficiency with cardiovascular disease, such as inflammation, smooth muscle cell proliferation, vascular calcification, effects on platelets and on the renin-

Address for correspondence: Sara Holmberg, Department of Research and Development, Region Kronoberg, Växjö, Sweden and Division of Occupational E-mail: sara.holmberg@kronoberg.se

Receivd: 3 November 2016; accepted: 20 February 2017; first published on May 2017 angiotensin system [8]. Vitamin D has immune-modulating effects resulting in a reduced pro-inflammatory state [12]. The inflammatory system is an important part of the complex regulating network maintaining allostasis in the stress response, and also affects cardiovascular function [13].

The main source of vitamin D is cutaneous conversion of promolecules into active vitamin D (mainly 25-Hydroxyvitamin $\mathrm{D}_{3}$ ) as a result of ultraviolet radiation from exposure to the sun. Additional sources are natural dietary content, vitamin food fortification and supplements. The latitude of geographical location is of importance for obtaining sufficient sunlight for the synthesis of active vitamin D. Seasonal variation in vitamin D levels have been illustrated in the Nordic countries $[14,15]$ and in the United Kingdom where high prevalence of deficient vitamin D levels have been found during winter and spring [16]. In the Nordic countries, exposure to the sun is below critical level for half of the year. In such areas, studying links between vitamin D and health and disease could be appropriate. Taking season into account for blood sampling is therefore crucial. A recent Swedish study provides observational evidence for avoidance of sun exposure as a risk factor for all-cause mortality [17].

Despite medical and public health advances, cardiovascular diseases are still common and severe among the middleaged and elderly. Swedish farmers have been identified as 
an occupational group with a low relative risk of IHD [18, 19], and similar observations are reported from Finland [20] and the USA [21]. Farmers work outdoors more than many other occupation; therefore, the impact of vitamin D could be a potential explanatory factor worth further investigation $[22,23]$.

The aim of the presented study is to investigate whether vitamin $\mathrm{D}$ is associated with IHD among rural middle-aged men in Sweden.

\section{MATERIALS AND METHOD}

Study population. A nested case-control study was performed within a population-based cohort of Swedish farmers and non-farming rural residents. A prospective cohort study was established in 1989 with the intention of studying the health and health-promoting factors in relation to farming. All male farmers born between 1930-1949, living in 9 selected rural municipalities in the southern half of Sweden, were identified from the Swedish National Farm Register. The areas were chosen to represent a variety of farm types and with consideration of known geographical cardiovascular disease gradients throughout the country [24]. Non-farming referents matched by age, gender and residential area were identified in the National Population Register. Altogether, 2,350 men met the criteria of occupational activity, and 1,220 farmers and 1,130 non-farmers were included in the cohort.

In 1990-91, the entire cohort was invited to take part in an extensive baseline health survey, with a participation rate of $76 \%$ [25]. The survey included questionnaires, medical interviews, physical tests and blood sampling, and for practical reasons spread out over a year, and performed by specially trained research personnel. The survey was therefore not a part of any regular health examinations.

Outcomes. Outcomes were from national health registers, and mortality, number of fatalities and causes of death obtained from the National Cause of Death Register. Morbidity, number of admissions to hospitals with main diagnosis, and up to 7 additional diagnoses for the years $1989-2009$ was obtained from the Hospital Patient Register. Diagnoses were noted according to the International Classification of Disease (ICD), Swedish version (9 $9^{\text {th }}$ edition, 1989 - 1996 [26], $10^{\text {th }}$ edition, $\left.1997-2009\right)$ [27]. In addition, diagnoses from outpatients departments at hospitals registered for 2001 2009 were retrieved and included in the same manner as for the inpatient register. No information on diagnoses in primary care was available.

Cases and controls. In the cohort, all men deceased or diagnosed with IHD were identified during the 20 years of follow-up. All available diagnoses were used and the number of individuals deceased or diagnosed with IHD counted at least once. IHD was defined by ICD-9 code $410-414$ and ICD-10 code I20-I25. Altogether, 276 men were included as cases with IHD.For each case, one aged matched control without any cardiovascular disease (no IHD diagnosis, no other cardiovascular or stroke diagnosis and no diabetes diagnosis) over the 20 year follow-up, was selected.

Blood sampling and analysis. Serum blood samples were non-fasting, centrifuged and refrigerated at $4^{\circ} \mathrm{C}$ at the examination site, and transported to the same laboratory in Uppsala for analyses of blood lipids (total s-cholesterol and s-triglycerides) within 3 days of sampling. Blood samples were frozen for later analysis.

The analysis of vitamin D was performed using a method previously described by Gustafsson et al. [28]. Briefly, aliquots of $100 \mu \mathrm{l}$ serum were precipitated with acetonitrile and centrifuged. Labeled 25-hydroxyvitamin D3 was used as the internal standard. The samples were analyzed by LC/MS/MS. In all analytical batches, in-house prepared quality control (QC) samples and chemical blanks were analyzed. The control samples were checked against controls (Chromsystems Instruments \& Chemicals GmbH; MassCheck $^{\oplus}$, Gräfelfing, Germany; DEQAS vitamin D External Quality Assessment Scheme, Endocrine Laboratory, Charing Cross Hospital,London, UK).

Background variables/potential confounders. At the baseline survey, weight and height of each respondent was measured with standard procedures, and body mass index (BMI) calculated. Blood pressure was measured twice with mechanical blood pressure equipment (Trim line LIC ${ }^{\circ}$ ) after 5 minutes of supine rest, and the average recorded. Physical work capacity was determined by a sub-maximal work test on a bicycle ergometer [29]. Tobacco habits were assessed in structured interviews, and for the current analyses dichotomized as current daily smoking versus no smoking. Educational level was classified on a 5-grade scale according to a self-report questionnaire. Experienced work demands were assessed by the job content questionnaire according to Karasek [30].

Statistical analyses. Differences in baseline characteristics between cases and controls were analyzed using t-test for continuous data and $\mathrm{chi}^{2}$-test for ordinal data.

Vitamin D was normally distributed, but the levels varied considerably according to the month of blood sampling (Fig. 1); therefore, measured vitamin $\mathrm{D}$ was adjusted for the month of sampling. The mean vitamin $\mathrm{D}$ was calculated for each month of the year. The monthly mean was then subtracted from each individual vitamin D measurement. Hence, the adjusted vitamin $\mathrm{D}$ varied around zero, with negative values for individuals with measured vitamin D

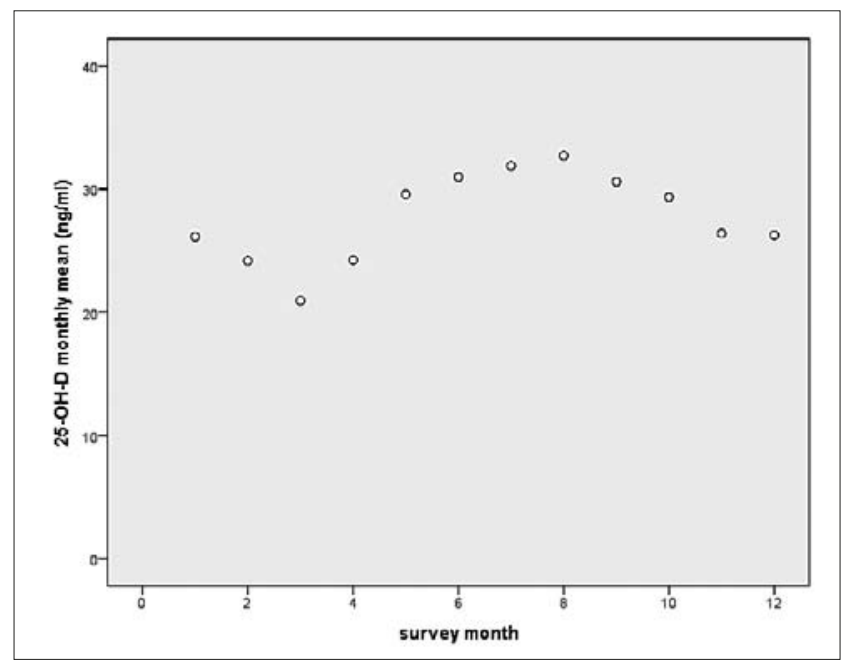

Figure 1. Variation in vitamin D level over the year (month $1=$ January, month $12=$ December $)$ in the total study population $(n=529)$ 
below the monthly mean, and positive values for individuals with vitamin $\mathrm{D}$ above the monthly mean.

Adjusted vitamin D was divided into quartiles according to the distribution among the controls. Associations between vitamin $\mathrm{D}$ (in quartiles) and background variables at baseline were analyzed with ANOVA for continuous data, and $\mathrm{chi}^{2}$ test for categorical data among the controls. The crude association between vitamin D and IHD was explored in a cross- tabulation with a chi ${ }^{2}$-test and illustrated in a diagram.

The associations between vitamin $\mathrm{D}$ at baseline and IHD were evaluated by logistic regression models generating odds ratios (OR) and 95\% confidence intervals (CI). First, a model with measured vitamin $\mathrm{D}$ was applied and second, a model with month-adjusted vitamin D in order to illustrate the effect of and need for adjusting the measurements. The quartile with the lowest vitamin D levels was defined as the reference category. Potential confounders (smoking, BMI, blood pressure, blood lipids, physical capacity, education, occupation, work demands) were included in the logistic regression models with forward stepwise entrance of variables in such a way that only variables significantlyinfluencing the model were kept in the final step (probability for stepwise entry $\mathrm{p}<0.05$ and removal $\mathrm{p}<0.10$ ).

All analyses were performed using IBM SPSS ${ }^{\circledast}$ Statistics 20. All tests were two-tailed and $\mathrm{p}<0.05$ defined as statistically significant. The study was approved by the Regional Ethical Committee at Lund University.

\section{RESULTS}

Vitamin D measurements were obtained for 529 individuals. The mean vitamin D in the study population was $28.2 \mathrm{ng} / \mathrm{ml}$ (to convert to nanomoles per litre, multiply by 2.496 ) with measurements ranging from $6.2 \mathrm{ng} / \mathrm{ml}-65.0 \mathrm{ng} / \mathrm{ml}$. No significant difference in measured vitamin $\mathrm{D}$ was found between cases and controls (Tab. 1). Background variables were associated with IHD in predicted directions. There were fewer farmers and more smokers among the IHD cases, and the cases experienced lower work demands, had a higher BMI and a lower physical work capacity at baseline. The cases also had higher blood pressure as well as higher serum cholesterol and triglycerides.

Adjusted vitamin D ranged from minus $22.0 \mathrm{ng} / \mathrm{ml}$ $38.8 \mathrm{ng} / \mathrm{ml}$. Few associations were found between vitamin $\mathrm{D}$ and background variables among the controls (Tab. 2). Individuals with only elementary compulsory education were over-represented in the highest vitamin D quartile, and the proportion of farmers was lower. The mean measured vitamin $\mathrm{D}$ among farmers was $27.1 \mathrm{ng} / \mathrm{ml}$, and among nonfarmers - $29.6 \mathrm{ng} / \mathrm{ml}(\mathrm{p}=0.001)$.

The distribution of absolute numbers of cases with IHD across vitamin $\mathrm{D}$ (adjusted by month of sampling) in quartiles is illustrated in Figure 2. Fewer cases with IHD were found in the highest quartile of vitamin D ( $\mathrm{p}=0.048$, crude analysis).

The risk of IHD was significantly lower in the highest quartile of month-adjusted vitamin D $(\mathrm{OR}=0.46 ; 95 \% \mathrm{CI}$ $0.25-0.84 ; \mathrm{p}=0.012$ ) after including systolic blood pressure, s-cholesterol, BMI and occupation (farmer versus nonfarmer) in the model (Tab. 3). The potential confounders; education, work demands, daily smoking, physical work capacity, diastolic blood pressure and triglycerides, were tested for, but did not reach significance to enter the final
Table 1. Baseline characteristics of cases with ischemic heart disease (IHD) and controls free of cardiovascular disease over 20 years of follow-up

\begin{tabular}{lcccccccc}
\hline & Cases IHD $(\mathrm{n}=276)$ & \multicolumn{3}{c}{ Controls $(\mathrm{n}=276)$} & \\
\hline & $\mathrm{n}$ & $\begin{array}{c}\text { mean } \\
\text { or \% }\end{array}$ & sd & $\mathrm{n}$ & $\begin{array}{c}\text { mean } \\
\text { or \% }\end{array}$ & sd & $\mathrm{p}^{1}$ \\
\hline $\begin{array}{l}\text { Vitamin D (serum 25-OH-D), } \\
\mathrm{ng} / \mathrm{ml}\end{array}$ & 263 & 27.6 & 8.2 & 266 & 28.8 & 9.0 & 0.095 \\
\hline
\end{tabular}

\begin{tabular}{llllll}
\hline Low vitamin $\mathrm{D}(<20 \mathrm{ng} / \mathrm{ml}), \%$ & 44 & 16.7 & 47 & 17.7 & 0.77 \\
\hline
\end{tabular}

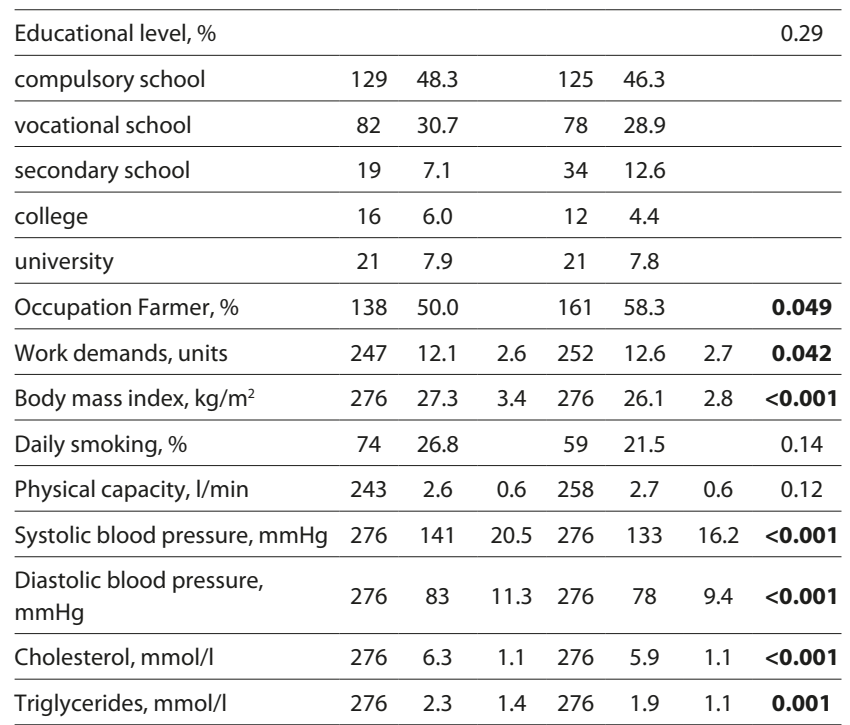

${ }^{1} \mathrm{t}$-test for continuous data and $\mathrm{chi}^{2}$-test for ordinal data.

Table 2. Background variables at baseline in relation to vitamin $D$ quartiles ${ }^{1}$ among controls $(n=266)$

\begin{tabular}{lccccc}
\hline & \multicolumn{5}{c}{ month-adjusted vitamin $\mathrm{D}^{2}$} \\
\cline { 2 - 6 } & $\mathrm{Q} 1$ & $\mathrm{Q} 2$ & $\mathrm{Q} 3$ & $\mathrm{Q} 4$ & $\mathrm{P}^{3}$ \\
\hline Compulsory school only, \% & 50.0 & 43.3 & 33.8 & 58.1 & $\mathbf{0 . 0 4 4}$ \\
\hline Occupation Farmer, \% & 71.2 & 62.7 & 55.2 & 50.0 & $0.071^{4}$ \\
\hline Work demands, units, mean & 12.5 & 12.0 & 13.2 & 12.5 & 0.10 \\
\hline Body mass index, mean & 26.0 & 26.1 & 26.2 & 26.0 & 0.98 \\
\hline Daily smoking, \% & 21.2 & 22.7 & 16.4 & 25.8 & 0.62 \\
\hline Physical capacity, I/min, mean & 2.7 & 2.8 & 2.7 & 2.8 & 0.64 \\
\hline Systolic blood pressure, mmHg, mean & 133 & 135 & 133 & 132 & 0.70 \\
\hline Diastolic blood pressure, mmHg, mean & 78 & 78 & 79 & 78 & 0.82 \\
\hline Cholesterol, mmol/l, mean & 6.0 & 5.8 & 5.9 & 6.1 & 0.62 \\
\hline Triglycerides, mmol/l, mean & 2.0 & 1.8 & 1.8 & 2.1 & 0.40 \\
\hline
\end{tabular}

${ }^{1}$ measured 25-OH-D level adjusted by month for blood sampling.

${ }^{2} \mathrm{Q} 1=$ lowest to $-3.72 \mathrm{ng} / \mathrm{ml}, \mathrm{Q} 2=-3.72$ to $1.02 \mathrm{ng} / \mathrm{ml}, \mathrm{Q} 3=1.02$ to $7.62 \mathrm{ng} / \mathrm{ml}, \mathrm{Q} 4=7.62 \mathrm{ng} / \mathrm{ml}$ to highest

${ }^{3} \mathrm{chi}^{2}$-test for categorical variables and ANOVA for continues variables.

${ }^{4} \mathrm{p}$ for trend $=0.009$

model. No dose-response relationship was observed in the four quartiles. When applying the model on measured nonadjusted vitamin $D$ in quartiles, the same tendency was found but the results did not reach significance. The cut-off for the highest quartile of measured vitamin D was $34.5 \mathrm{ng} / \mathrm{ml}$. 


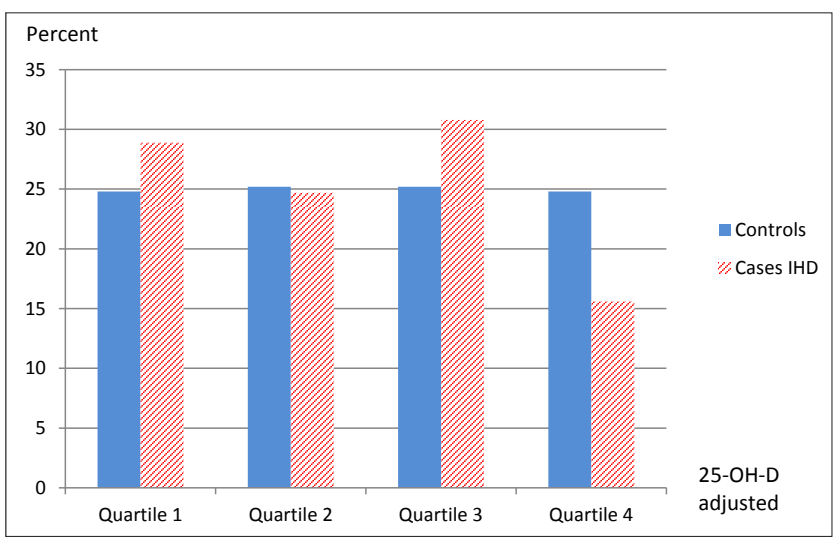

Figure 2. Distribution of absolute number of cases with ischemic heart disease according to vitamin D (adjusted by month of sampling) in quartiles at baseline $\left(p=0.048\right.$, chi $^{2}$-test $)$

Table 3. Risk of ischemic heart disease over 20 years of follow up in relation to measured vitamin $\mathrm{D}$ and in relation month-adjusted vitamin $\mathrm{D}$ levels at baseline

\begin{tabular}{|c|c|c|c|c|c|c|}
\hline \multicolumn{4}{|c|}{$\begin{array}{l}\text { Crude model } \\
\qquad(n=529)\end{array}$} & \multicolumn{3}{|c|}{$\begin{array}{l}\text { Adjusted model } \\
\qquad(n=430)\end{array}$} \\
\hline $\begin{array}{c}\mathrm{n} \\
\text { cases }\end{array}$ & $\begin{array}{c}\mathrm{n} \\
\text { controls }\end{array}$ & $\mathrm{OR}^{2}$ & $95 \% \mathrm{Cl}^{3}$ & $\begin{array}{c}\mathrm{n} \\
\text { total }\end{array}$ & OR & $95 \% \mathrm{Cl}$ \\
\hline
\end{tabular}

Measured vitamin $\mathrm{D}^{4}$

\begin{tabular}{lllllllll}
\hline quartile 1 & 70 & 68 & 1 & & 112 & 1 & \\
\hline quartile 2 & 74 & 65 & 1.11 & $0.69-1.77$ & 118 & 1.13 & $0.65-1.95$ \\
\hline quartile 3 & 72 & 68 & 1.03 & $0.64-1.65$ & 113 & 1.03 & $0.59-1.81$ \\
\hline quartile 4 & 47 & 65 & 0.70 & $0.42-1.16$ & 87 & 0.65 & $0.36-1.21$ \\
\hline
\end{tabular}

Adjusted vitamin $\mathrm{D}^{5}$

\begin{tabular}{ccccccccc}
\hline quartile 1 & 76 & 66 & 1 & & 116 & 1 & \\
\hline quartile 2 & 65 & 67 & 0.84 & $0.52-1.35$ & 109 & 0.70 & $0.40-1.23$ \\
\hline quartile 3 & 81 & 67 & 1.05 & $0.66-1.67$ & 117 & 1.10 & $0.63-1.91$ \\
\hline quartile 4 & 41 & 66 & $\mathbf{0 . 5 4}$ & $\mathbf{0 . 3 2}-\mathbf{0 . 9 0}$ & 88 & $\mathbf{0 . 4 6}$ & $\mathbf{0 . 2 5}-\mathbf{0 . 8 4}$
\end{tabular}

${ }^{1}$ multiple logistic regression adjusted for systolic blood pressure, s-cholesterol, body mass index and occupation (farmer vs. non-farmer).

index and occup
2

${ }^{3} 95 \%$ confidence interva

${ }^{4}$ quartiles based on serum levels of 25-OH-D among controls at baseline. Q1=lowest to $22.3 \mathrm{ng} / \mathrm{ml}, \mathrm{Q} 2=22.3$ to $28.4 \mathrm{ng} / \mathrm{ml}, \mathrm{Q} 3=28.4$ to $34.5 \mathrm{ng} / \mathrm{ml}, \mathrm{Q} 4=34.5 \mathrm{ng} / \mathrm{ml}$ to highest

quartiles based on month-adjusted 25-OD-D among controls at baseline Q1=lowest to $-3.72 \mathrm{ng} / \mathrm{ml}, \mathrm{Q} 2=-3.72$ to $1.02 \mathrm{ng} / \mathrm{ml}, \mathrm{Q} 3=1.02$ to $7.62 \mathrm{ng} / \mathrm{ml}, \mathrm{Q} 4=7.62 \mathrm{ng} / \mathrm{ml}$ to highest

\section{DISCUSSION}

It was found that men in the highest quartile of vitamin $\mathrm{D}$, when adjusted for time of sampling, had approximately half the risk of IHD after controlling for known risk factors. The obtained results agree with those of Giovanni et al. who used an immunoassay methodology [6]. In their larger study with a similar design, they reported about half the risk of IHD for men with vitamin D levels of at least $30 \mathrm{ng} / \mathrm{ml}$, or above. Giovanni et al. found a graded dose-response relationship that was not be observed in the data for the presented study. In the Framingham offspring study that followed 1,739 men and women over 5.4 years, the risk of cardiovascular events was 1.62 times higher among those with low vitamin $\mathrm{D}(<15 \mathrm{ng} / \mathrm{ml})$ with a graded dose response [31]. Other researchers have found a non-linear inverse association with the risk of cardiovascular mortality, starting at vitamin D concentrations below $30 \mathrm{ng} / \mathrm{ml}[32]$. A U-shaped relationship has been suggested with the lowest risk of mortality at levels $30-49 \mathrm{ng} / \mathrm{ml}$ [33]. The American Institute of Medicine concluded in 2011 that the evidence regarding vitamin D and extraskeletal outcomes was inconsistent and inconclusive regarding causality[34].

Although a stronger association of vitamin D deficiency with fatal cardiovascular disease than with non-fatal events has been reported [9], other large longitudinal population studies have found no significant associations with vitamin $D$ and cardiovascular mortality in adjusted models [33, 35,36]. Whether vitamin $\mathrm{D}$ deficiency is a causal risk factor for cardiovascular disease, or merely an indicator of poor health, is still an open question $[37,38]$.

It is well-known that serum concentrations of vitamin D vary during the year at higher latitudes. In the presented study, levels of vitamin $\mathrm{D}$ varied considerably in relation to month of sampling, and when this was accounted for, an association with IHD was revealed. This illustrates the need to take into account the season of blood when assessing vitamin D for populations or individuals at higher latitudes. Klingberg et al. reported a large seasonal variation in serum vitamin $\mathrm{D}$ in a cohort study of blood donors in Sweden [15]. During January - March, 58\% were below the threshold $50 \mathrm{nmol} / \mathrm{l}$ and $88 \%$ were below $75 \mathrm{nmol} / \mathrm{l}$, whereas the corresponding figures during July - September were $11 \%$ and $50 \%$. They also analyzed intra-individual seasonal variation by repeated measurements showing strong correlations indicating that each individual follow their own curve.

Of the background variables assessed in the current study, only education and occupation were associated with vitamin D when adjusted for month of sampling. Having only compulsory schooling was over-represented in the highest quartile of vitamin D. In unadjusted analysis in a large sample of the general population in USA, low socio-economic status was associated with higher risk of vitamin D deficiency, but this association was reversed after adjustment in multivariate analysis [33]. The authors identified physical activity and race as the main confounders behind their finding. Higher education might also be related to a more sun-protective behaviour, and this might differ between countries. Vitamin $\mathrm{D}$ has been found to be inversely correlated with smoking and with BMI, and positively correlated with physical activity $[6$, $15,33]$. In a study by Klingberg et al., physical activity was associated with higher serum concentrations of vitamin D during summer, but not during winter, indicating that the effect may be related to outdoor activities [15].

In the presented study, half of the participants were farmers, and contrary to the authors' preconception, the farmers had lower vitamin D levels, compared to non-farmers. A plausible explanation for this, despite farmers' high degree of outdoor work, might be that farmers have a more sun-protective behaviour. In a nationally representative sample of almost 6,000 adult US inhabitants, sun protective behaviours, such as staying in the shade and wearing long sleeve clothing, were associated with lower vitamin D levels [39]. This type of sun avoidance in everyday life is typical of Swedish traditional family farmers included in the cohort (personal knowledge). In addition, holiday visits to sunny destinations are associated with higher vitamin D levels [15], and this type of holidays might be less common among farmers who generally take fewer vacations (Holmberg, unpublished data). Accordingly, it is unlikely that the low relative risk of cardiovascular disease among farmers could be explained by good vitamin 
D status related to working outdoors. However, this question was not the focus of the current study and therefore not tested within the available data. The authors also did not have access to vitamin D measurements for the entire rural cohort of farmers and non-farmers.

Extensive evidence support the role of inflammatory mechanisms involved in atherosclerosis and $\operatorname{IHD}[40,41]$. Vitamin D has multiple immune modeling effects[42]: vitamin $\mathrm{D}$ and vitamin $\mathrm{D}$ binding protein (VDBP) decreases as part of the acute inflammatory systemic response as a negative acute phase reactant [43]. It has been hypothesized that low vitamin $\mathrm{D}$ may be a consequence rather than a cause of inflammatory disease[44]. VDBP was lower among farmers with musculoskeletal disorders than among rural referents in a plasma proteomic study of biomarkers of systemic inflammation [45]. The level of VDBP is also genetically derived [46]. The bioavailability of vitamin D varies depending on the binding protein. Low levels of vitamin D in connection with low levels of VDBP, therefore, may not necessarily indicate deficiency. Measurement of VDBP might be necessary in order to give a fair picture of status of vitamin D.

Based on the case control design, the analyses of background variables and vitamin $\mathrm{D}$ were performed solely among the controls in order to look for independent associations. Since the matching between cases and controls were performed only on age, and the age span was rather narrow, the rational for paired tests was considered limited. Each measurement of vitamin $\mathrm{D}$ was adjusted by month of sampling before entering the logistic regression. The variation in vitamin $\mathrm{D}$ levels was similar over seasons, and it was estimated that the categorization into quartiles was not affected by the adjustment. Vitamin D does not require any special storage conditions [47] and the long-term storage of serum does not affect the vitamin D serum levels [48].

A limitation of the presented study was that neither dietary intake nor supplements were taken into account. Some questionnaire based dietary data (dairy fat intake, intake of fruit and vegetables) was available for the participants, but this study was considered too small for robust analysis. Klingberg et al. found only weak associations between vitamin D levels and intake of vitamin D supplements [15]. The probable number of respondents taking supplements in this study population was very low. However, in Sweden, low-fat dairy products have been fortified with vitamin D for several decades.

The major strength of the current study is the prospective nested case-control design within a well-defined cohort. Baseline data was assessed in an extensive survey and rigorously checked. The partial non-response (missing data for separate variables) was generally low. Only register based hard end-points were used. Major known IHD risk factors were accounted for, but residual confounding related to, for example, diet, physical activity or sun exposure, cannot be ruled out.

\section{CONCLUSION}

It was found that rural Swedish men in the highest quartile of serum vitamin D had halved the relative risk of IHD, compared to those in the lowest quartile. The presented results conform well with the results obtained by other researchers, but the meaning and interpretation is uncertain. Much research remains to be undertaken in order to understand how vitamin $\mathrm{D}$ affects the risk of cardiovascular disease. Despite the fact that low levels of vitamin D are common in populations, to-date, no clear evidence for supplementation for treatment or prevention has been presented. Vitamin D is part of a very complex system involving inflammation, but the importance for cardiovascular epidemiology, public health and clinical work, remains to be resolved.

\section{Acknowledgements}

The authors wish to thank Agneta Kristensen, Åsa Amilon and Margareta Maxe for performing the chemical analyses, and Anna Lindgren, statistician at Lund University, for her contribution to the statistical analyses. The study was supported by the Medical Faculty at Lund University and the Swedish Research Council through projects grants and vthe SIMSAM Lund network.

\section{REFERENCES}

1. Holick MF, Chen TC. Vitamin D deficiency: a worldwide problem with health consequences. Am J Clin Nutr. 2008; 87(4): 1080S-6S.

2. Arnson Y, Amital H, Shoenfeld Y. Vitamin D and autoimmunity: new aetiological and therapeutic considerations. Ann Rheum Dis. 2007; 66(9): 1137-42.

3. Klampfer L. Vitamin D and colon cancer. World J Gastrointest Oncol. 2014; 6(11): 430-7.

4. Chowdhury R, Kunutsor S, Vitezova A, Oliver-Williams C, Chowdhury S, Kiefte-de-Jong JC, et al. Vitamin D and risk of cause specific death: systematic review and meta-analysis of observational cohort and randomised intervention studies. BMJ. 2014; 348: g1903.

5. Schottker B, Jorde R, Peasey A, Thorand B, Jansen EH, Groot L, et al. Vitamin D and mortality: meta-analysis of individual participant data from a large consortium of cohort studies from Europe and the United States. BMJ. 2014; 348: g3656.

6. Giovannucci E, Liu Y, Hollis BW, Rimm EB. 25-hydroxyvitamin D and risk of myocardial infarction in men: a prospective study. Arch Intern Med. 2008; 168(11): 1174-80.

7. Wang L, Song Y, Manson JE, Pilz S, Marz W, Michaelsson K, et al. Circulating 25-hydroxy-vitamin D and risk of cardiovascular disease: a meta-analysis of prospective studies. Circ Cardiovasc Qual Outcomes. 2012; 5(6): 819-29.

8. Kunadian V, Ford GA, Bawamia B, Qiu W, Manson JE. Vitamin D deficiency and coronary artery disease: a review of the evidence. Am Heart J. 2014; 167(3): 283-91.

9. Perna L, Schottker B, Holleczek B, Brenner H. Serum 25-hydroxyvitamin $\mathrm{D}$ and incidence of fatal and nonfatal cardiovascular events: a prospective study with repeated measurements. J Clin Endocrinol Metab. 2013; 98(12): 4908-15.

10. Schnatz PF, Manson JE. Vitamin D and cardiovascular disease: an appraisal of the evidence. Clin Chem. 2014; 60(4): 600-9.

11. Bjelakovic G, Gluud LL, Nikolova D, Whitfield K, Wetterslev J, Simonetti RG, et al. Vitamin D supplementation for prevention of mortality in adults. Cochrane Database Syst Rev. 2014; 1: CD007470.

12. van Etten E, Mathieu C. Immunoregulation by 1,25-dihydroxyvitamin D3: basic concepts. J Steroid Biochem Mol Biol. 2005; 97(1-2): 93-101.

13. Karatsoreos IN, McEwen BS. Psychobiological allostasis: resistance, resilience and vulnerability. Trends Cogn Sci. 2011; 15(12): 576-84.

14. Brustad M, Alsaker E, Engelsen O, Aksnes L, Lund E. Vitamin D status of middle-aged women at 65-71 degrees $\mathrm{N}$ in relation to dietary intake and exposure to ultraviolet radiation. Public Health Nutr. 2004; $7(2): 327-35$.

15. Klingberg E, Olerod G, Konar J, Petzold M, Hammarsten O. Seasonal variations in serum 25-hydroxy vitamin D levels in a Swedish cohort. Endocrine. 2015: DOI 10.1007/s12020-015-0548-3.

16. Hypponen E, Power C. Hypovitaminosis D in British adults at age 45 y: nationwide cohort study of dietary and lifestyle predictors. Am J Clin Nutr. 2007; 85(3): 860-8.

17. Lindqvist PG, Epstein E, Landin-Olsson M, Ingvar C, Nielsen K, Stenbeck M, et al. Avoidance of sun exposure is a risk factor for all- 
cause mortality: results from the Melanoma in Southern Sweden cohort. J Intern Med. 2014; 276(1): 77-86.

18. Thelin A. Morbidity in Swedish farmers, 1978-1983, according to national hospital records. Soc Sci Med. 1991; 32(3): 305-9.

19. Thelin N, Holmberg S, Nettelbladt P, Thelin A. Mortality and morbidity among farmers, nonfarming rural men, and urban referents: a prospective population-based study. Int J Occup Environ Health. 2009; 15(1): 21-8.

20. Notkola VJ, Husman KR, Laukkanen VJ. Mortality among male farmers in Finland during 1979-1983. Scand J Work Environ Health. 1987; 13(2): 124-8.

21. Stark AD, Chang HG, Fitzgerald EF, Riccardi K, Stone RR. A retrospective cohort study of mortality among New York State Farm Bureau members. Arch Environ Health. 1987; 42(4): 204-12.

22. Devgun MS, Paterson CR, Johnson BE, Cohen C. Vitamin D nutrition in relation to season and occupation. Am J Clin Nutr. 1981; 34(8): 1501-4.

23. Azizi E, Pavlotsky F, Vered I, Kudish AI. Occupational exposure to solar UVB and seasonal monitoring of serum levels of 25-hydroxy vitamin D3: a case-control study. Photochem Photobiol. 2009; 85(5): 1240-4.

24. Nerbrand C, Aberg H, Rosen M, Tibblin G. [Regional mortality variations in middle Sweden]. Lakartidningen. 1985; 82(46): 4004-8.

25. Holmberg S, Stiernström EL, Thelin A, Svärdsudd K. Musculoskeletal symptoms among farmers and non-farmers: a population-based study. Int J Occup Environ Health. 2002; 8(4): 339-45.

26. Socialstyrelsen. International Classification of Diseases, Ninth Revision (ICD-9), Swedish version. Stockholm, Sweden: Liber/Allmänna förlaget; 1986.

27. Socialstyrelsen. International statistical classification of diseases and related health problems, Tenth revision (ICD-10), Swedish version. Uppsala, Sweden: Almqvist \& Wiksell; 1997.

28. Gustafsson P, Rylander L, Lindh CH, Jonsson BA, Ode A, Olofsson P, et al. Vitamin D Status at Birth and Future Risk of Attention Deficit/ Hyperactivity Disorder (ADHD). PLoS One. 2015; 10(10): e0140164.

29. Tornvall G. Assessment of physical capabilities. Acta Physiologica Scandinavica. 1963; 58(201): 17-55.

30. Karasek R, Brisson C, Kawakami N, Houtman I, Bongers P, Amick B. The Job Content Questionnaire (JCQ): an instrument for internationally comparative assessments of psychosocial job characteristics. J Occup Health Psychol. 1998; 3(4): 322-55.

31. Wang TJ, Pencina MJ, Booth SL, Jacques PF, Ingelsson E, Lanier K, et al. Vitamin D deficiency and risk of cardiovascular disease. Circulation. 2008; 117(4): 503-11.

32. Schottker B, Haug U, Schomburg L, Kohrle J, Perna L, Muller H, et al. Strong associations of 25-hydroxyvitamin D concentrations with allcause, cardiovascular, cancer, and respiratory disease mortality in a large cohort study. Am J Clin Nutr. 2013; 97(4): 782-93.

33. Melamed ML, Michos ED, Post W, Astor B. 25-hydroxyvitamin D levels and the risk of mortality in the general population. Arch Intern Med. 2008; 168(15): 1629-37.
34. Ross AC, Manson JE, Abrams SA, Aloia JF, Brannon PM, Clinton SK, et al. The 2011 report on dietary reference intakes for calcium and vitamin $\mathrm{D}$ from the Institute of Medicine: what clinicians need to know. J Clin Endocrinol Metab. 2011; 96(1): 53-8.

35. Kilkkinen A, Knekt P, Aro A, Rissanen H, Marniemi J, Heliovaara M, et al. Vitamin D status and the risk of cardiovascular disease death. Am J Epidemiol. 2009; 170(8): 1032-9.

36. Messenger W, Nielson CM, Li H, Beer T, Barrett-Connor E, Stone K, et al. Serum and dietary vitamin D and cardiovascular disease risk in elderly men: a prospective cohort study. Nutr Metab Cardiovasc Dis. 2012; 22(10): 856-63.

37. Schottker B, Saum KU, Perna L, Ordonez-Mena JM, Holleczek B, Brenner $H$. Is vitamin $\mathrm{D}$ deficiency a cause of increased morbidity and mortality at older age or simply an indicator of poor health? Eur J Epidemiol. 2014; 29(3): 199-210.

38. Verdoia M, Schaffer A, Sartori C, Barbieri L, Cassetti E, Marino P, et al. Vitamin D deficiency is independently associated with the extent of coronary artery disease. Eur J Clin Invest. 2014; 44(7): 634-42.

39. Linos E, Keiser E, Kanzler M, Sainani KL, Lee W, Vittinghoff E, et al. Sun protective behaviors and vitamin D levels in the US population: NHANES 2003-2006. Cancer Causes Control. 2012; 23(1): 133-40.

40. Pai JK, Pischon T, Ma J, Manson JE, Hankinson SE, Joshipura K, et al. Inflammatory markers and the risk of coronary heart disease in men and women. N Engl J Med. 2004; 351(25): 2599-610.

41. Christodoulidis G, Vittorio TJ, Fudim M, Lerakis S, Kosmas CE. Inflammation in coronary artery disease. Cardiol Rev. 2014; 22(6): 279-88.

42. Di Rosa M, Malaguarnera M, Nicoletti F, Malaguarnera L. Vitamin D3: a helpful immuno-modulator. Immunology. 2011; 134(2): 123-39.

43. Waldron JL, Ashby HL, Cornes MP, Bechervaise J, Razavi C, Thomas OL, et al. Vitamin D: a negative acute phase reactant. J Clin Pathol. 2013; 66(7): 620-2.

44. Albert PJ, Proal AD, Marshall TG. Vitamin D: the alternative hypothesis. Autoimmun Rev. 2009; 8(8): 639-44.

45. Ghafouri B, Carlsson A, Holmberg S, Thelin A, Tagesson C. Biomarkers of systemic inflammation in farmers with musculoskeletal disorders; a plasma proteomic study. BMC Musculoskelet Disord. 2016; 17: 206.

46. Powe CE, Evans MK, Wenger J, Zonderman AB, Berg AH, Nalls M, et al. Vitamin D-binding protein and vitamin D status of black Americans and white Americans. N Engl J Med. 2013; 369(21): 1991-2000.

47. Colak A, Toprak B, Dogan N, Ustuner F. Effect of sample type, centrifugation and storage conditions on vitamin D concentration. Biochem Med (Zagreb). 2013; 23(3): 321-5.

48. Agborsangaya C, Toriola AT, Grankvist K, Surcel HM, Holl K, Parkkila $\mathrm{S}$, et al. The effects of storage time and sampling season on the stability of serum 25-hydroxy vitamin D and androstenedione. Nutr Cancer. 2010; 62(1): 51-7. 